\title{
An undiagnosed case of placenta percreta presenting as a massive hemoperitoneum in obstetric emergency
}

\author{
Shamim Khandaker, MD,FNB ${ }^{1}$
}

Keywords: Cesarean section, hysterectomy, placenta percreta, hemoperitoneum

Abstract

Placenta accreta and placenta percreta are rare causes of serious obstetric hemorrhage. Here we report an undiagnosed case of placenta percreta presenting to the emergency department with shock in the third trimester of pregnancy. Emergency laparotomy with caesarean hysterectomy and blood transfusion are the key steps in successful management.

${ }^{1}$ North Bengal Medical College, Sushrutanagar, Darjeeling, Pin-734012.

Disclosure: No conflict of interest

\section{Introduction}

Placenta percreta is a rare complication of pregnancy which is potentially lifethreatening for both the mother and the fetus. In patients with placenta previa, the risk of accreta is $10 \%$ to $25 \%$ with one prior caesarean section. ${ }^{1}$ Uterine rupture due to placenta percreta is very rare, with an incidence of 1 in 5,000 pregnant women. $^{2}$ This is to report a case of a previously undiagnosed placenta percreta which presented with shock due to uterine perforation and fetal distress.

\section{Case report}

A 24 year old married Indian female; G2P1A0L1; post low transverse cesarean delivery pregnancy presented with shock to the emergency department. Her gestational age was 36 wks by LMP. She had a history of open myomectomy before her first pregnancy. The details of the operative note regarding the location and extent of myomectomy were not available. Her first pregnancy was uneventful except for breech presentation resulting in an uncomplicated caesarean section. The exact location of the placenta was not documented in her current antenatal note, but it was not a case of placenta previa. The antenatal period was uneventful until her presentation at 36 weeks of gestation with severe abdominal pain. Her ultrasonography report at 28 wks of gestation suggested posterior low lying placenta; but no evidence of placenta accreta was given in that report. After 30 wks she had no regular antenatal check-up; as she was scheduled for an antenatal check-up and elective low transverse caesarean

Please cite this paper as: Khandaker S. An undiagnosed case of placenta percreta presenting as a massive hemoperitoneum in obstetric emergency. Proc Obstet Gynecol. 2014;4(1): Article 3 [ 5 p.]. Available from: http://ir.uiowa.edu/pog/. Free full text article.

Corresponding author: Shamim Khandaker M.S (O\&G), Flat no A4; Pratima apartments; Anandapuri block A, 45 Jessore Road, Barasat, Kolkata, Pin 700124. shamim_khandaker@yahoo.co.in.

Copyright: (c) 2013 Khandaker. This is an open-access article distributed under the terms of the Creative Commons Attribution License, which permits unrestricted use, distribution, and reproduction in any medium, provided the original author and source are credited. 
delivery at 37 weeks.

Clinical examination: She presented with a history of sudden onset of abdominal pain and diminished fetal movement for the past 2 hours. She was very pale, ill looking and hemodynamically unstable with blood pressure $80 / 50$ and pulse $120 / \mathrm{min}$ and low volume. Abdominal pain was continuous and generalized. On abdominal examination, the uterine contour was intact. It was difficult to define uterine scar tenderness. The fetal heart rate could not be localized. The abdomen was mildly distended with muscle guarding present. An emergency ultrasonography would probably have been advisable; however, the acute emergent presentation of the case precluded an ultrasound as we were resuscitating her and preparing for an emergency laparotomy. On vaginal examination, the cervix was uneffaced with no dilatation or vaginal bleeding.

Diagnosis \& treatment: The decision for laparotomy was made with the provisional diagnosis of uterine scar rupture or concealed placental abruption. She was taken to the operating theatre within 30 minutes from the time of admission. On laparotomy, a massive hemoperitoneum was observed. Her previous Caesarean section scar was intact. Lower segment caesarean section was done revealing clear amniotic fluid. A live male of 2.75 $\mathrm{kg}$ was delivered with Apgar score of 1 at 1 minute. The baby was resuscitated by the neonatologist and after initial resuscitation with bag mask ventilation 5 minute Apgar score was 5 and subsequently 10 minute Apgar score was 8 . The baby was sent to the NICU and kept under observation for 2 days before being given to the mother. The uterus was elevated out of the laparotomy incision. The placenta was densely adhered to the posterior aspect of the uterus. The myometrium and serosa were penetrated by the placenta, with evidence of uterine perforation with placenta percreta at the posterior surface of uterus. (Figure 1) The decision was made to perform a total abdominal hysterectomy in view of the placenta percreta. The specimen was sent for histopathology which showed placental villi extending deeply into and through the myometrium of the lower uterine segment, suggestive of placenta percreta in the lower uterine segment.

Post operatively, she was transferred to the Intensive Care Unit and received a blood transfusion of 4 units. She recovered well with transfer to the general ward on the 3rd post-operative day and an uneventful post-operative period. She was discharged from the hospital on 7th post-operative day. At the time of discharge her hemoglobin was $8.5 \mathrm{gm} \%$ and she was advised to take oral iron therapy for three months.

\section{Discussion}

The overall incidence of placenta accreta is 1 in 533 pregnancies. ${ }^{3}$ Placenta percreta is the rarest form of placental abnormalities $(7 \%$ of pathologically adherent placenta). ${ }^{4}$ In placenta percreta, the decidua basalis is partially or completely absent, and the chorionic villi invade the entire myometrium up to the serosa. ${ }^{5}$ The increasing incidence of placenta accreta may be associated with the increased rate of caesarean deliveries. Other 
predisposing factors include: complicated uterine curettage, manual removal of the placenta, and myomectomy. ${ }^{6}$ Placenta percreta may present in the antenatal period with intraperitoneal or intravesical bleeding. Intraperitoneal bleeding mimics placental abruption or uterine rupture. ${ }^{7}$

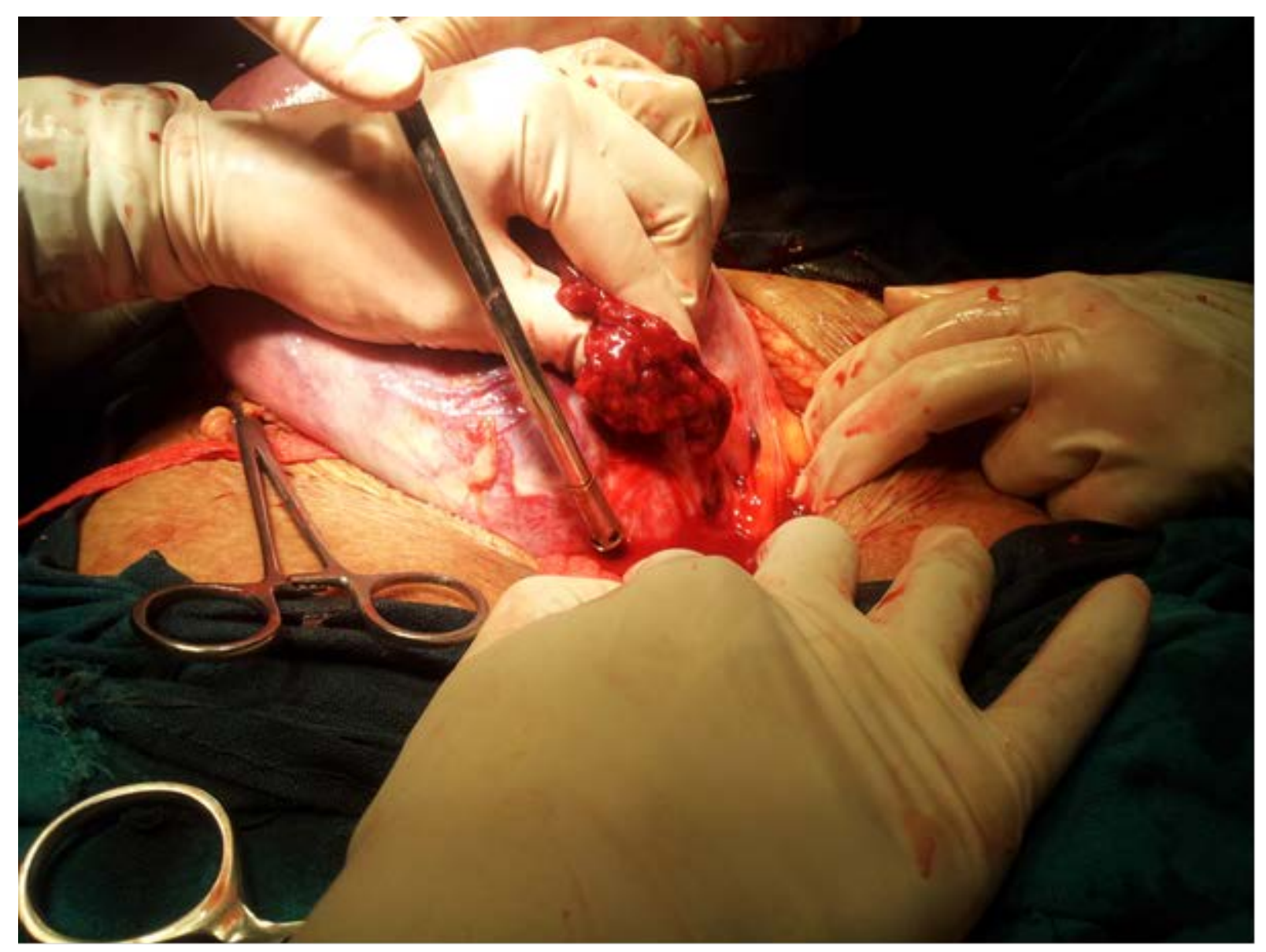

Figure 1- Placenta percreta perforating serosa in posterior surface of uterus

Gray-scale ultrasound and color Doppler imaging are the first-line imaging modalities for the diagnosis of placenta accreta. MRI is used as an adjunct tool when sonographic examination is equivocal or when the placenta cannot be reliably visualized on sonography. The 2D ultrasound criteria for the diagnosis of placenta accreta in at-risk patients are obliteration of the retroplacental echolucent zone, abnormal prominent placental lacunae and thinning or disruption of the hyperechoic uterine serosa-bladder interface. ${ }^{8}$ 3D power Doppler imaging increases the sensitivity of the diagnosis of placenta accreta with the following parameters:

hypervascularity, intraplacental inseparable cotyledonal and intervillous circulations, 
tortuous vascularity with chaotic branching. ${ }^{9}$ MRI may show signs of abnormal placentation as defined by thinning, indistinctness of the myometrium, loss of the thin T2 dark uteroplacental interface, irregular thick intraplacental T2 dark bands (result of fibrin deposition), marked placental heterogeneity, and bulging of the lower uterine segment. ${ }^{10}$ In the present case, routine ultrasonography likely did not diagnose the percreta as the area of involvement by percreta was very small and in the posterior surface. (Figure 1) We speculate that it is possible that the previous myomectomy which may involve the uterine cavity could give rise abnormal placentation in this case; although a recent study showed that prior myomectomy is not associated with higher risks of either uterine rupture or placenta accreta. ${ }^{11}$ In general, the area of placenta percreta-induced uterine rupture exhibits high vascularization; which can give rise to massive hemorrhage as in this case. Caesarean hysterectomy is recommended in the case of lifethreatening severe hemorrhage. ${ }^{6}$ Conservative management may be an option in order to prevent peripartum hysterectomy and to preserve fertility, as long as bleeding remains minimal. Leaving the placenta in situ undisturbed is a consideration with administration of prophylactic antibiotic and prophylactic postpartum oxytocics. There appears to be no universal agreement on the requirement for methotrexate when the placenta is retained; although it may hasten the resolution of placenta. $^{11}$ Follow-up to ensure the resolution of placental tissue is done with a combination of clinical assessment, ultrasound examination and serial serum ß-hCG assay. If the area of accreta is focal and the majority of the placenta has been removed, then a wedge resection of the area can be performed. Evidence suggests that bilateral uterine artery embolization is less likely to be successful in cases of abnormal placentations. ${ }^{12}$ Planning for delivery should involve a team including a maternal fetal specialist, an anesthesiologist, a urologist, a hematologist, an interventional radiologist, and a pelvic surgeon to optimize patient outcome. Delivery should be done in a specialized tertiary center with adequate resources, including those for massive transfusion anticipating need for hysterectomy. ${ }^{13}$

\section{Conclusions}

Previously undiagnosed placenta percreta is rare but might present as an unexpected hemoperitoneum. Rapid diagnosis, blood product replacement and emergency laparotomy with caesarean hysterectomy are the key steps in successful management.

\section{References}

1. Chattopadhyay SK, Kharif H, Sherbeeni MM. Placenta praevia and accreta after previous caesarean section. Eur J Obstet Gynecol Reprod Biol. 1993 Dec 30;52(3):151-6. PubMed PMID: 8163028.

http://dx.doi.org/10.1016/00282243(93)90064-J

2. Gardeil F, Daly S, Turner MJ. Uterine rupture in pregnancy reviewed. Eur J Obstet Gynecol Reprod Biol. 1994 Aug;56(2):107-10. PubMed PMID: 7805960 .

http://dx.doi.org/10.1016/00282243(94)90265-8 
3. Wu S, Kocherginsky M, Hibbard JU. Abnormal placentation: twenty-year analysis. Am J Obstet Gynecol. 2005 May;192(5):1458-61. PubMed PMID: 15902137.

http://dx.doi.org/10.1016/j.ajog.2004.12. 074

4. Sultana N, Mohyuddin S, Jabbar T. Management and maternal outcome in morbidly adherent placenta. J Ayub Med Coll Abbottabad 2011;23(2):93-96.

5. Moriya M, Kusaka H, Shimizu K, Toyoda $\mathrm{N}$. Spontaneous rupture of the uterus caused by placenta percreta at 28 weeks of gestation: a case report. J Obstet Gynaecol Res. 1998 Jun;24(3):211-4. PubMed PMID: 9714992.

http://dx.doi.org/10.1111/j.14470756.1998.tb00077.x

6. Miller DA, Chollet JA, Goodwin TM. Clinical risk factors for placenta previaplacenta accreta. Am J Obstet Gynecol. 1997 Jul;177(1):210-4. PubMed PMID: 9240608.

http://dx.doi.org/10.1016/S00029378(97)70463-0

7. Vyjayanthi S, Rajesh U, Bloomfield TH. Haemoperitoneum due to placenta percreta in the third trimester mimicking placental abruption. J Obstet Gynaecol. 2002 Nov;22(6):690-1. PubMed PMID: 12554272.

http://dx.doi.org/10.1080/014436102762 062394

8. Comstock $\mathrm{CH}$, Love JJ Jr, Bronsteen RA, Lee W, Vettraino IM, Huang RR, Lorenz RP. Sonographic detection of placenta accreta in the second and third trimesters of pregnancy. Am J Obstet Gynecol. 2004 Apr;190(4):1135-40. PubMed PMID: 15118654. http://dx.doi.org/10.1016/j.ajog.2003.11. 024
9. Shih JC, Palacios Jaraquemada JM, Su YN, Shyu MK, Lin CH, Lin SY, Lee CN. Role of three-dimensional power Doppler in the antenatal diagnosis of placenta accreta: comparison with grayscale and color Doppler techniques. Ultrasound Obstet Gynecol. 2009 Feb;33(2):193-203. doi: 10.1002/uog.6284. PubMed PMID: 19173239.

10. Lax A, Prince MR, Mennitt KW, Schwebach JR, Budorick NE. The value of specific MRI features in the evaluation of suspected placental invasion. Magn Reson Imaging. 2007 Jan;25(1):87-93. Epub 2006 Nov 14. PubMed PMID: 17222719. http://dx.doi.org/10.1016/j.mri.2006.10.0 07

11. Gyamfi-Bannerman C, Gilbert S, Landon MB, Spong CY, Rouse DJ, Varner MW, Caritis SN, Meis PJ, Wapner RJ, Sorokin $Y$, Carpenter $M$, Peaceman AM, O'Sullivan MJ, Sibai BM, Thorp JM, Ramin SM, Mercer BM; Eunice Kennedy Shriver National Institute of Child Health and Human Development (NICHD) Maternal-Fetal Medicine Units (MFMU) Network. Risk of uterine rupture and placenta accreta with prior uterine surgery outside of the lower segment. Obstet Gynecol. 2012 Dec;120(6):1332-7. doi: http://10.1097/AOG.0b013e318273695b . PubMed PMID: 23168757; PubMed Central PMCID: PMC3545277.

12. Armstrong CA, Harding S, Dickinson JE. Clinical aspects and conservative management of placenta accreta. The Obstetrician \& Gynaecologist. 2004;6(3):132-7. DOI: 10.1576/toag.6.3.132.26994

13. Publications Committee, Society for Maternal-Fetal Medicine, Belfort MA. Placenta accreta. Am J Obstet Gynecol. 2010 Nov;203(5):430-9. doi: 10.1016/j.ajog.2010.09.013. PubMed PMID: 21055510. 